\title{
Quando o campo é o patrimônio: notas sobre a partici pação de antropólogos nas questões do patrimônio*
}

\author{
Regina A breu**
}

\begin{abstract}
Resumo: É crescente o número de antropólogos que fazem pesquisas no campo do Patrimônio. Do ponto de vista reflexivo, muitos destes pesquisadores têm contribuído com análises acuradas sobre a questão do valor e de suas atribuiçães no contexto social, uma vez que os bens aulturais patrimonializados são aqueles com forte conteúdb simbólico, capazes de expressar e/ou representar naçöes, regiões, etnias ou grupos sociais. Por autro lado, O fato do campo do Patrimônio constituir-se também enquanto um campo de intervenção social faz com que, em muitos casos, à perspectiva reflexiva dos pesquisadbres sejam adicionados outros interesses e demandas. Entre os antropólogos que estudam, refletem e produzem sobre 0 Patrimônio e os antropólogos que se colocam como agentes ativos do Patrimônio podemos mapear correntes, vertentes e tendências. Nos anos mais recentes, tanto no contexto nacional quanto intemacional, estas tensões e/ou conjugacões entre atividades reflexivas e práticas vêm ganhando novos contomos com a implementação de uma política voltada para o inventário e registro do chamado Patrimônio Intangível. Particularmente neste campo, os antropólogos vêm ocupando espaço expressivo e sendo instadbs a fomular critérios e metooblogias capazes de ampliar a patrimonialização das diferenças allturais. O artigo visa mapear as diferentes posições dos antropólogos no campo do Patrimônio discutindo as tensões e/ou conjugaçães entre diversas formas de atuação, reflexivas e/cu práticas.
\end{abstract}

Palavras-chave: patrimônio; antropologia; memória social.

\section{A presentação}

$\mathrm{Na}$ última el eição da diretoria da A ssociação B rasileira de A ntropologia, aprovamos em assembléia a criação do G rupo de Trabalho de Patrimônio, ligado à presidência da entidade. Essa resolução expressa não apenas o crescimento de uma área de estudos, mas a repentina abertura de um vasto mercado de trabal ho para

\footnotetext{
* Este artigo foi originalmente apresentado como comunicação no seminário Quando o Campo é o A rquivo, organizado pelo CPDOC/FGV nos dias 25 e 26 de novembro de 2004. A gradeço o convite dos professores Celso Castro e Olívia Gomes, organizadores do evento.

** Professora adjunta de Antropologia Social da Universidade do Estado do Rio de Janeiro (Unirio). E-mail: regabreu@ism.com.br
}

antropólogos em um território antes hegemonicamente marcado pela atuação de arquitetos, historiadores e, em menor escala, sociólogos. Temos diante de nós um imenso desafio: como atuar em um campo onde os antropólogos são convocados tanto para atividades reflexivas como para atividades práticas de intervenção, como emitir pareceres relativos a processos de tombamento e registros do patrimônio intangível ou até mesmo formular políticas no interior de organismos estatais?

Com o intui to de traçar al gumas estratégias e al ertar para os cuidados necessários para dar conta dessas novas demandas, o Grupo de Trabalho de Patrimônio, coordenado por M anuel Ferreira L ima Filho, do M estrado em G estão do 
Patrimônio Cultural da U niversi dade Católica de Goiás, e por mim, que atuo no Mestrado em M emória Social da Unirio, reuniu-se informalmente na última reunião da $A$ npocs, em Caxambu, em outubro de 2004. A reunião contou com a participação de José R eginaldo Santos Gonçalves, do IFCS-UFRJ; de Maria Eunice $M$ aciel e de Ruben George Oliven, ambos do Programa de Pós-Graduação em A ntropologia Social da U niversidade Federal do R io G rande do Sul; de J osé Guilherme M agnani, do Departamento de A ntropologia da USP; de A lexandre Corrêa, do Departamento de A ntropologia da Universidade Federal do M aranhão; de Julie Cavignac, do Departamento de A ntropologia da U niversidade Federal do Rio Grande do N orte. Esse pequeno núcleo, formado por antropólogos atuantes no campo do patrimônio, seja com teses defendidas sobre o tema, seja com trabalhos de pesquisa ou incursões diversas na área, el aborou uma primeira lista, com um levantamento de antropólogos pesquisando sobre o tema ou no campo do patrimônio. Chegou-se a algumas dezenas de nomes em universidades e instituições em todo o B rasil, entre el es antropólogos antes associados a outras áreas, como Roque de Barros Laraia, cujos principais trabalhos relacionam-se à etnologia indígena, mas que recentemente se tornou professor do M estrado em Gestão do Patrimônio Cultural da U niversidade Católica de Goiás, ou Gilberto Velho e L uiz Fernando Duarte, ambos do PPGA S-M N/ UFRJ, que participaram do Consel ho do Instituto do Patrimônio Histórico e A rtístico Nacional em diferentes períodos. 0 nome de maior destaque é o de Antonio A ugusto A rantes, doutor pela U nicamp com uma tese sobre patrimônio, que assumiu este ano a presidência do Instituto do Patrimônio Histórico e Artístico Nacional, atuando duplamente como autoridade acadêmica e formulador de políticas.

Quais as razões do crescimento repentino da inserção de antropólogos nessa nova área de trabal ho e de estudos? Como os antropólogos vêm atuando nesse setor? 0 que significa para um antropólogo fazer do patrimônio o seu campo? De que maneiras isso vem se dando?

\section{A perspectiva reflexiva}

2.1 Trabalhos produzidos em universidades e centros de pesquisa

Algumas teses e pesquisas sobre 0 patrimônio elaboradas por antropólogos, que datam dos anos 80 , contribuíram para abrir uma nova área de estudos. 0 trabal ho de A ntonio A ugusto A rantes, P roduzindo o passado, publicado em 1984, é uma referência nesse sentido. Outra pesquisa importante conduzida por um antropólogo éa de J osé R eginal do Santos Gonçalves, intitulada Retórica da perda - Os discursos do patrimônio cultural no Brasil, originalmente tese de doutorado defendida no Departamento de A ntropologia da Universidade de Virginia, nos Estados U nidos, e publicada em 1996 pela Editora da UFRJ. A mbos os trabalhos são considerados marcos da reflexão antropológica sobre o patrimônio no B rasil. U m tema antes tratado por arquitetos e historiadores passava a ser focalizado sob o viés da antropologia. A tônica destes trabal hos consistiu em apresentar uma visão desnaturalizada de um campo eivado por ideologias e paixões, sobretudo de cunho nacionalista. A rantes e Gonçalves esforçaram-se por propor uma outra leitura de construções discursivas particularmente eficazes na fabricação de uma memória e de uma identidade nacionais. A o mostrar o quanto essas construções discursivas são datadas na história do 0 cidente, ea maneira como elas foram sendo construídas por intermédio de políticas específicas no interior do aparelho de Estado, esses trabal hos abriram nova perspectiva no campo dos estudos de patrimônio. Particularmente 0 trabalho de Gonçalves iniciou um diálogo importante com antropólogos americanos de linhagem interpretativista como Richard $\mathrm{H}$ andler e James Clifford e toda uma área de estudos antropológicos voltada para memória social, museus, práticas de colecionamento e patrimônios. Essas pesquisas problematizaram sobretudo o tema do patrimônio nacional, evidenciando sua relação com o caráter arbitrário das nações modernas como "comunidades imaginadas" (Benedict A nderson, 1989) e a necessidade de construções discursivas e al egorias capazes de expressar certa ilusão de 
homogeneidade e coesão para os Estadosnações.

A estratégia de $G$ onçalves foi analisar duas narrativas centrais na formulação de políticas do patrimônio no Brasil, a de Rodrigo M ello Franco de Andrade - um dos idealizadores e primeiro diretor do Sphan, que inspirou sua política de 1937 a 1979 - e a de Aloísio $M$ agalhães - que esteve à frente do Sphan/PróM emória por um curto período, de 1979 a 1983, mas que foi decisivo para sua transformação. A o tomar o patrimônio como um campo no sentido etnográfico, essas duas pesquisas evidenciaram as estratégias de construção ou de invenção de bens considerados dignos para representar a memória e a identidade nacionais e as justificativas retóricas que passaram a ser introjetadas pelos agentes do patrimônio e pela sociedade brasileira. A lguns conceitos foram especialmente introduzidos, formando um pensamento antropológico sobre o patrimônio, como o conceito de "objetificação cultural" de Richard Handler, quando esse autor sugere a "coisificação" de culturas e tradições em modernos contextos nacionais, ou seja, uma certa tendência em pensar as culturas como coisas, em representá-las com base em determinados bens materiais como edificações, paisagens ou objetos museológicos cuidadosamente escoIhidos e retirados de seus contextos originais para serem ressignificados em outros. 0 patrimônio seria, portanto, o lugar em que agentes estatais especialmente treinados coletariam fragmentos de tradições culturais diversas para reuni-los em um conjunto artificialmente criado voltado para representar a idéia de uma totalidade cultural artificialmente criada expressa pela idéia de nação.

Outro conceito importante, desenvolvido especialmente por J ames Clifford, em ensaio sobre sistemas de arte e cultura, seria o conceito de "prática de colecionamento", entendido como uma prática universal, presente em todas as sociedades humanas e relacionada à necessidade vital dos homens em classificar e hierarquizar. A reflexão de Clifford éinspiradora para a pesquisa seminal de Gonçalves, que sinaliza nas construções discursivas estudadas (de Rodrigo M ello Franco de Andrade e de A loísio M agalhães) os bens considerados dignos de colecionamento, com o intuito de formar um mosaico "autenticamente" nacional. 0 tema da autenticidade é colocado em relevo. G onçalves, utilizando-se de estratégia etnográfica e tomando os discursos de Rodrigo Mello Franco de A ndrade e de A loísio M agalhães como os de informantes selecionados, em uma pesquisa de campo produz a relativização dessa categoria fundante das modernas ideologias ocidentais.

0 tema do patrimônio emerge assim como um lugar de construção de valores e, como tal, extremamente plástico e variável. 0 bem cultural "autêntico", como representação metafórica da totalidade nacional, é desnaturalizado e a sua face ideológica e ficcional, descortinada. Gonçalves está atento para a dimensão literária e provisória de ideologias que procuram se firmar como verdades cal cadas em noções positivistas da ciência. N esse sentido, apóia-se na reflexão de Hayden White acerca dos mecanismos de produção da moderna historiografia ena fixação da idéia presente em toda a história linear de que todas as nações devam obrigatoriamente ter um passado. 0 patrimônio, em certa modalidade discursiva (no caso a de Rodrigo M ello Franco de A ndrade), seria a de representação ou de objetificação desse passado. Por outro lado, o patrimônio na modalidade discursiva de A loísio M agal hães estaria mais fixado na noção de cultura e de diversidade cultural, com ênfase em um tempo presente capaz de, por si só, se eternizar. A nação, em ambas construções discursivas, é apresentada como uma entidade dotada de coerência e continuidade. Essa coerência seria menos um dado ontológico do que 0 efeito daquelas estratégias narrativas.

Enquanto o trabalho de Gonçalves é centrado no estudo de categorias de pensamento, em discursos, narrativas, o trabal ho de A rantes volta-se para os contextos sociais e intitucionais em que as políticas de patrimônio nacionais são construídas. A rantes está interessado em desvendar as relações sociais envolvidas nesse processo de patrimonialização. Esses dois trabalhos seminais abrem caminho para que outros antropólogos se interessem pel o tema do patrimônio. $\mathrm{N}$ a década de 1990 , duas pesquisas são especialmente relevantes. A primeira de autoria de Silvana Rubino (U nicamp), intitulada As fachadas da história: os antecedentes, a 
criação e os trabalhos do Serviço do Patrimônio Histórico e Artístico Nacional, 19371968, apresentada como dissertação de mestrado ao Departamento de Filosofia e Ciências Humanas da U niversi dade E stadual de Campinas, em janeiro de 1991. A segunda produzida por M arisa Velloso M. Santos, 0 tecido do tempo: a idéia de patrimônio cultural no Brasil (1920-1970), apresentada como tese de doutorado ao Departamento de A ntropologia da U niversidade de B rasília, em 1992.

É preciso observar que, do final dos anos 80 até pelo menos a primeira metade dos anos 90 , houve uma expressiva voga de trabalhos refletindo sobre o tema da nação. Talvez esse surto reflexivo sobre o nacional tenha sido em parte motivado pela grande quantidade de produções de historiadores e cientistas sociais franceses, por ocasião das comemorações do bicentenário da Revolução Francesa. É desse período a publicação da coletânea de textos organizados em quatro grossos volumes pelo historiador francês Pierre Nora, da École des Hautes Études en Sciences Sociales, e intitulada Lugares de memória. Em cada um desses volumes - três consagrados ao tema da nação e um voltado para a república -, historiadores consagrados dedicaram-se a esquadrinhar 0 longo processo de construção do Estado-nação francês em todos os seus mais ínfimos detalhes, como o culto aos heróis, os manuais de história da França para crianças, os guias de viagem para formar os cidadãos franceses na noção de pátria e território e, claro, toda a máquina estatal que se voltou para a invenção do patrimônio francês, desde os primeiros protestos de Victor H ugo em 1832, quando ameaçavam destruir os prédios históricos e monumentais, e os primeiros projetos de Violet Le Duc, engenheiro e arquiteto francês, que iniciou todo o processo de restauração de Paris, para que a cidade conservasse para sempre sua feição eloqüente de berço dos novos ideais que passariam a reger 00 cidente.

$\mathrm{N}$ as palavras de Pierre Nora, as comemorações do bicentenário da Revolução Francesa incitaram o autor a tecer um inventário dos lugares onde a memória nacional na França tomou corpo e que, pela vontade dos homens ou pelo trabalho dos séculos, sobreviveram como os símbolos mais evidentes: festas, emble- mas, monumentos e comemorações, mas também elogios, dicionários e museus. A noção de "lugares de memória" construída ao longo de três anos - de 1978 a 1981 -, em um seminário dirigido por Nora na École, foi um marco importante nos estudos que procuravam relacionar memória e história. No entender de N ora, os "lugares de memória" surgiram nas sociedades ocidentais modernas como fragmentos de uma memória em franco desaparecimento. A ação da história moderna calcada em uma representação linear do tempo e em uma reconstrução sempre problemática do que não mais existe, teria condenado ao fim a memória coletiva. 0 fato de se falar tanto em memória seria para Nora um sintoma de que esta não mais existiria, tendo sido substituída pela história. As sociedades ocidentais modernas seriam 0 resultado de uma mutilação sem retorno representada pelo fim das coletividades-memória, que eram as sociedades tradicionais, por excelência as sociedades camponesas, nas quais cada gesto cotidiano era vivido como uma repetição religiosa de atos extremamente significativos para a coletividade, onde havia uma identificação carnal do ato e do significado. Com certo tom nostál gico, $\mathrm{N}$ ora propôs-se a discorrer sobre os estilhaços ou fragmentos daquela que seria o último esforço de construção de uma memória coletiva no O cidente, a memória nacional.

Estes lugares precisam ser compreendidos no sentido pleno do termo, do mais material e concreto, como os monumentos aos mortos e os A rquivos nacionais, ao mais abstrato e intel ectualmente construído, como a noção de linhagem, de geração, ou mesmo de região e de "homem-memória". D os lugares institucionalmente sagrados, como R eims ou o Panteão, aos humildes manuais de nossas infâncias republicanas. Das crônicas de Saint-D ennis do século XIII, ao Tesouro da Língua Francesa, passando pelo Louvre, pela M arselhesa e a Enciclopédia L arousse. (N ora, 1984)

Essa voga de estudos dessacral izadores do ideal de nação teve talvez no campo da história sua maior repercussão, mas circulou também entre antropólogos e cientistas sociais que desenvolveram estudos reflexivos sobre os mecanismos de constituição do nacional entre nós. A final, se a república francesa comemo- 
rava duzentos anos em 1989, no mesmo ano a república verde-amarela completava cem anos. $\mathrm{Na}$ perspectiva da história, é dessa época o trabalho, por exemplo, de José Murilo de Carval ho, A formação das almas, evidenciando em minúcias o processo de elaboração dos símbolos nacionais: a bandeira, o hino, as alegorias, os monumentos (Carvalho, 1990). Por essa ocasião passava-se em revista a história da formação das nações modernas. 0 historiador Éric Hobsbawm publicou a Era dos impérios, tematizando o período que se abriu em 1870, quando, na Europa, tiveram lugar as grandes transformações que desencadearam novas relações entre os indivíduos. A partir de então, todos deviam fidelidade a um ente abstrato e distante: o Estado-nação. O utro trabal ho do historiador inglês desse período foi A invenção das tradições, no qual propunha pesquisar sobre pequenas invenções necessárias à consolidação dos Estados nacionais, como alegorias e trajes típicos. 0 ensaio sobre a invenção do traje típico dos escoceses e de toda a tradição envolvida inspirou pesquisas de historiadores e antropólogos sobre o papel das identidades regionais e locais na construção dos símbolos nacionais (Hobsbawm, 1984).

O utros trabal hos de antropologia, embora não se dedicassem exatamente ao tema do patrimônio nacional, voltaram-se para o estudo da criação de muitos outros símbolos necessários à formação dos novos cidadãos. C abe registrar o trabal ho do antropólogo R uben Geoge Oliven sobre a invenção do gaúcho, em certa parte inspirado no ensaio de Hobsbawm. Oliven utiliza a perspectiva antropológica para desvendar a maneira pela qual a tradição gaúcha foi criada com festas, datas e trajes típicos. A antropóloga $\mathrm{M}$ aria E unice $\mathrm{M}$ aciel, do mesmo departamento de Oliven, segue trilha semelhante.

U ma outra linha de investigação que se inaugurou no período dos anos 80 e 90 foi 0 estudo dos museus e das práticas de colecionamento de objetos museológicos. Também em parte inspirados na voga dos estudos sobre a formação dos Estados-nações e seus símbolos, esses estudos congregaram historiadores e antropólogos. Os museus e suas coleções eram entendidos como partes expressivas dos patri- mônios nacionais. Com relação à perspectiva antropológica de estudos de museus e práticas de colecionamento, devemos registrar que a tendência auto-reflexiva da antropologia também contribuiu para o foco nessa área. Do projeto editorial organizado por G eorgeStocking J r sobre a história da antropologia foi lançado em 1985 um número especial sobre museus e práticas de colecionamento na antropologia. 0 livro $O$ bjects and others. Essays on museums and material culture, terceiro volume da série, trouxe artigos sobre a estreita relação da antropologia com os museus, desde o nascimento da disciplina. Vale destacar 0 artigo de I ra J acknis focalizando o trabalho de Franz Boas como curador de exposições em museus etnográficos; 0 artigo de Richard Handler, que se tornou clássico nos estudos do patrimônio sobre 0 processo de construção do patrimônio em Québec, e, por fim, 0 artigo de J ames Clifford sobre a prática de colecionamento dos objetos "dos outros" nos grandes museus e os problemas advindos desses deslocamentos dos objetos com relação a seus contextos de origem. ${ }^{1}$

Tomar os museus e as coleções de museus em uma perspectiva antropológica, procurando perceber esses lugares de memória como elementos importantes do sagrado nacional, consistiu no meu objetivo na dissertação de mestrado apresentada ao PPGAS-M useu Nacional em 1990, com o título Sangue, nobreza e política no templo dos imortais: um estudo antropológico da Coleção Miguel Calmon no Museu Histórico Nacional e publicada em livro em 1996 sob o título A fabricação do imortal. Nesse trabalho, tomei o M useu Histórico $\mathrm{N}$ acional em seus primeiros anos, que coincidem com o período em que esteve à frente da instituição seu fundador e principal idealizador, o escritor G ustavo B arroso (1922-1959). Como estratégia metodológica para entender o significado da memória nacional que ali era construída, focalizei o processo de

\footnotetext{
1. Os títulos dos artigos são respectivamente: JACKNIS, Ira. Franz Boas and exhibits: On the limitation of the museum method of anthropology; HANDLER, Richard. On having a culture: nationalism and the preservations of Québec's Patrimoine; CLIFFORD, J ames. Objects and selves - An afterword. In: STOCKING, J r., George W. Objects and others. Essays on museums and material culture. London: University of Wisconsin Press, 1985.
} 
doação e incorporação de uma grande coleção de um político influente da Primeira R epública, $M$ iguel Calmon. Utilizando como principal referência o Ensaio sobre a dádiva de $M$ arcel M auss e suas reflexões sobre reciprocidade, pude perceber o museu como um lugar de trocas simbólicas e rituais entre os agentes sociais que, nesses movimentos, construíam uma versão da história do Brasil e fabricavam personagens históricos. A experiência de trabal har com uma perspectiva antropológica para entender a lógica de funcionamento de uma instituição produtora de memória foi muito rentável. Sob essa perspectiva, foi possível fazer uma leitura do museu e de suas coleções até certo ponto original. N esse trabalho, dialoguei com a perspectiva de J osé Reginaldo Gonçalves, analisando, assim como ele, a construção discursiva de um fundador de uma instituição vol tada para o patrimônio nacional.

No meu caso específico, de maneira diversa de $G$ onçalves, o objeto era um museu. Focalizar a criação e os primeiros anos de funcionamento dessa instituição foi uma estratégia deliberada de eleger para a análise os nativos do passado. Isto por dois motivos. 0 primeiro relacionado a uma certa tendência dos estudos do período, que consistia em fazer um inventário do campo do patrimônio com base no discurso dos fundadores. 0 segundo motivo deveu-se ao fato de que na época eu era funcionária do M useu Histórico N acional, o que dificultava uma proposta de estudar a instituição em uma abordagem sincrônica. A familiaridade com colegas museólogos e historiadores não ensejava uma pesquisa das práticas de colecionamento na contemporaneidade. A perspectiva antropológica voltada para uma leitura do passado pareceu-me mais adequada como estratégia de entrada no campo. Estudar a instituição com a qual eu mantinha um vínculo empregatício colocava-me de certo modo em um lugar diferente dos meus colegas, pois produzia um distanciamento e uma relativização de suas práticas e projetos. Olhar 0 museu como um lugar de produção da memória e indagar sobre a modalidade de memória que ali vinha sendo elaborada, com que fins e objetivos, poderia parecer um tema até certo ponto ameaçador para aqueles que faziam da prática museológica e histórica o seu ofício, que acreditavam na eficácia dessas instituições como produtoras de símbolos e narrativas. Falar de um lugar de fora e situar-se ao mesmo tempo dentro da instituição com seus problemas e suas vicissitudes não me parece uma tarefa simples. $\mathrm{Na}$ minha experiência particular, muito me auxiliou o fato de eu não atuar em cargo de direção e, de certo modo, permanecer protegida na Divisão de Estudos e Pesquisas, setor que ocupava certo lugar de retaguarda na institui ção.

$\mathrm{M}$ as o olhar antropológico rel ativizador, eu diria mesmo, dessacralizador, criou por vezes certos embaraços. Quando trabalhamos com discursos fundadores e com figuras carismáticas de pais fundadores, em quaisquer que sejam os campos, a polêmica é inevitável. Esquadrinhar o pensamento de Gustavo B arroso, figura eminente no museu, a partir do qual tudo ou quase tudo ali foi gerado, representava tocar no emblema de alguns e algumas colegas de trabalho. Esse intelectual abriu um campo novo no B rasil ao tecer com colaboradores as bases para uma escola de museologia no país. A minha sorte, neste caso, é que, como toda figura emblemática, não havia unanimidade sobre sua contribuição. E o fato também de G ustavo B arroso ter adotado na política atitudes conservadoras, com passagem pelo movimento integralista, tornava-o antipático para certos segmentos. A conclusão da pesquisa trouxe elementos capazes de descortinar al guns dos pressupostos que orientaram a formação de um acervo considerado representativo de uma certa versão da história do $B$ rasil. Todos entenderam que eu falava de um museu do passado, que não mais existia e, desse modo, minha pesquisa foi vista como uma contribuição sobre a história do museu e o pensamento de seu fundador. Em se tratando de uma dissertação de mestrado foi recebida com muito respeito, e até admiração, por meus colegas.

$\mathrm{N}$ a ocasião, o historiador U I piano T. B ezerra de Menezes, do Departamento de História da Universidade de São Paulo, estava à frente do M useu Paulista da USP e propunha que os museus tematizassem suas próprias histórias e analisassem seus acervos. UIpiano chegou a realizar uma exposição no M useu Paulista sobre a construção do próprio museu e as estratégias de definição e incorporação de seu monumental acervo ao longo da história. Essa vertente de 
estudos e exposições, de certo modo antisacralizadoras, causaram certo espanto entre al guns museól ogos e historiadores acostumados a ocultar os bastidores de suas instituições em reservas técnicas e arquivos históricos. A opção de UIpiano foi muito debatida na época e, certamente, contribuiu para que meu trabalho fosse bem recebido no campo da museologia e da história. A partir de então, passei sistematicamente a ser convidada para simpósios de museologia, notadamente de museus históricos. Ulpiano convidou-me para escrever um ensaio nos Anais do Museu Paulista, em um número dedicado à história e à cultura material. ${ }^{2}$

A revista, que só foi publicada após sua saída da direção da instituição, em 1994, foi concebida com uma abordagem reflexiva sobre os museus históricos, seus acervos e exposições. No ensaio de abertura, o próprio U I piano abria os debates apresentando "um leque extremamente aberto de problemas" do museu histórico contemporâneo, sendo os principais referentes às possibilidades "de participação do museu histórico na produção do conhecimento histórico" e, "nessa perspectiva", o funcionamento da exposição museológica (M enezes, 1994). Em linhas gerais, U I piano adotava uma perspectiva extremamente crítica com relação aos museus históricos, procurando exorcizar seus fantasmas como monumentos celebrativos da memória nacional. 0 pano de fundo dos estudos sobre museus e patrimônios do ponto de vista acadêmico era, portanto, promissor. A ntropólogos, historiadores e cientistas sociais descobriam 0 potencial desses "lugares de memória" como conformadores de visões de mundo e contribuidores de "invenções de tradições nacionais".

N esse período dos anos 80 e 90, muitos dos autores citados dialogaram em diferentes momentos no Grupo de Trabal ho sobre Pensamento Social B rasileiro, nas reuniões da A npocs em Caxambu. Além dos trabalhos citados, o tema do patrimônio foi objeto de reflexão de teses e pesquisas de sociólogos e cientistas políticos. É importante destacar o trabalho de M yrian Sepúlveda dos Santos, que focal izou o tema dos museus em dissertação apresentada

2. ABREU, Regina. História de uma coleção: M iguel Calmon e o M useu Histórico Nacional. Anais do M useu Paulista. História e Cultura M aterial. Jan./dez. 1994, SP, Ed. USP. em 1989 no Mestrado em Ciência Política no I uperj, intitulada História, tempo e memória: um estudo sobre museus a partir da observação feita no Museu Imperial e no Museu Histórico Nacional. Outro trabalho relevante sobre o tema do patrimônio no período focalizado é o de Cecília L ondres, apresentado como tese de doutorado em Sociologia da Cultura na UnB e publicado em 1997 pela editora da UFR J sob o título Patrimônio em processo. Trajetória da política federal de preservação no Brasil. M yrian Sepúlveda dos Santos preocupou-se em refletir sobre construções da história, em diferentes momentos, de dois museus históricos. Cecília L ondres, pelo contrário, não refletiu sobre a história, mas adotou uma perspectiva "primordialmente histórica", tomando como "objeto de pesquisa o processo de construção do patrimônio histórico e artístico no Brasil, considerado enquanto uma prática social produtiva, criadora de valor em diferentes direções" (Fonseca, 1997, p. 19-20). Outro trabalho de reflexão sobre o patrimônio produzido ainda nesse período é o de $M$ arcia Chuva, também uma tese de doutorado de história apresentada na UFF. Em outro extremo do país, nesse mesmo período, na U niversidade Federal de Pernambuco, A lexandre Correa finalizava uma tese de doutorado em antropologia sobre o tema do patrimônio.

A crescente produção em torno dos discursos fundadores do patrimônio no B rasil geraram um seminário no início da década de 90 intitulado I deólogos do Patrimônio. A lém disso, foram organizadas algumas mesas-redondas e seminários nas reuniões da $\mathrm{A}$ ssociação $\mathrm{B}$ rasilei ra de A ntropologia para debater sobre memória, nação, patrimônio, museus, coleções. Nos anos seguintes, surpreendemo-nos com o crescente interesse na área de estudos do patrimônio. É claro que muito desse interesse se deveu ao fato de que muitos de nós mantivemos um trabalho nas universidades e fomos aos poucos introduzindo linhas de pesquisa vinculadas ao tema.

2.2 A abertura de cursos de pós-graduação em Memória e Patrimônio

A emergência do tema do patrimônio como objeto de reflexão nas universidades deu-se nos 
anos 90. A té então, este era um tema quase que circunscrito a instituições estatais como os museus e o I phan. N essas agências, formaramse ao longo dos anos pesquisadores e profissionais que se dedicaram a refletir sobre questões da memória e do patrimônio, mas quase sempre com uma perspectiva interessada de intervenção e construção do campo propriamente dito. $M$ uitos dos pesquisadores que se dedicaram a escrever dissertações e teses tiveram passagem, como eu, nessas instituições. Foi o diálogo com linhas de pesquisa nas universi dades que permitiu, por outro lado, arejar o debate interno dos órgãos voltados para a atuação no campo do patrimônio. Essa relação entre universidades e agências estatais tem sido uma constante no meio daqueles que escrevem sobre 0 assunto. José Reginaldo Gonçalves, por exemplo, foi chamado inúmeras vezes para falar no I phan sobre os "pais fundadores" do instituto e as principais políticas formuladas para a área no passado. No meu caso, participo ativamente de simpósios, mesas-redondas e publicações do M useu Histórico N acional e de outros museus. Recentemente, em jul ho deste ano, fui convidada para presidir uma mesa em reunião da Associação Internacional dos M useus H istóricos, no M useu Paulista, em São Paulo. Esses intercâmbios entre o pesquisador e as agências que configuraram o campo etnográfico de suas pesquisas são extremamente interessantes, mas muitas vezes provocam confusões e mal-entendidos. A perspectiva acadêmica, reflexiva, tem uma especificidade com relação ao trabal ho de atuação em uma área que, independentemente das relativizações que se possam fazer, funciona como instância canonizadora, formando ícones e símbolos da memória nacional. 0 diálogo, portanto, tem limites e muitas vezes é difícil precisá-los. Faz parte do jogo das agências do patrimônio a consagração por meio de ações de tombamentos de bens móveis e imóveis, listas de edificações a serem preservadas ou de objetos a serem recolhidos. As políticas de memória são o resultado de dinâmicas deliberadas de lembranças e esquecimentos. Valorizar objetos, entronizar personagens no panteão de uma construção discursiva da história, restaurar um quadro, um prédio ou um bai rro seguindo a opção de uma determinada época ou padrão arqui- tetônico é bem diferente de refletir sobre os mecanismos que levaram uma sociedade a valorizar aqueles objetos e não outros, ou de estudar sobre as escolhas dos quadros a serem restaurados e daqueles fadados à destruição, ou ainda observar criticamente que a restauração de um bairro ou de um complexo arquitetônico com base em determinados padrões estéticos não é suficiente para restaurar a "autenticidade original" desses espaços.

Desse modo, alguns pesquisadores que, como eu, originalmente desenvolveram seus interesses de pesquisa em museus ou agências de patrimônio perceberam a dificuldade em conciliar esses dois lugares ou práticas profissionais. No meu caso, tomei a decisão de trabaIhar na universidade, prestando concurso no final dos anos 90 para a Universidade Federal do Estado do Rio de J aneiro, onde ingressei em uma pós-graduação em memória social que ali havia sido criada por um grupo de historiadores. A perspectiva interdisciplinar do curso me atraiu. A lém do mais, eu não via, na ocasião, um interesse em estudos de memória e patrimônio nos Departamentos de A ntropologia das universidades no Rio de aneiro. Desse modo, a Unirio me pareceu uma boa opção. Cabe observar que o Centro de Ciências Humanas dessa universidade reúne al gumas faculdades singulares no panorama das universidades no R io de Janeiro, a saber, de M useologia, de Biblioteconomia e de A rquivologia, além de contar com uma Faculdade de H istória. A tuar nessas faculdades teve para mim um certo sabor de ser uma antropóloga fora do lugar, ou seja, de não contribuir diretamente para a formação de antropólogos ou cientistas sociais, que é, em geral, parte importante do trabalho dos antropólogos nas universidades. $M$ as esse trabalho abriu também para mim uma perspectiva de exercitar o ol har antropológico na qualificação do profissional que atua em áreas de gestão da memória e patrimônio.

Particularmente no curso de pós-graduação tem sido possível propor um trabalho reflexivo para alunos que são também profissionais da área. Esse procedimento tem servido como elemento propul sor de levantamento de questões que certamente vêm fazendo com que os profissionais enxerguem a inserção nas insti- 
tuições em que atuam sob novos ângulos. Trabalhar com museólogos, historiadores, arquivistas, bibliotecários, sociólogos, que são também técnicos de instituições como o A rquivo Nacional, a Biblioteca Nacional, o M useu do Índio, o M useu $\mathrm{N}$ acional, o M useu da Imagem e do Som, fazê-los dialogar entre si nos cursos, tem sido uma experiência enriquecedora. Ao mesmo tempo, permite uma certa liberdade para levar adiante minhas próprias pesquisas, sem obrigatoriamente ter de me dedicar a atividades que outrora me envolviam quando funcionária do Museu Histórico Nacional ou em minha passagem pelo Iphan e pela Coordenação de Folclore e Cultura Popular do M inC, tais como realização de exposições museológicas e pareceres técnicos.

Outros grupos de pesquisa sobre patrimônio, memória, museus e práticas de colecionamento foram sendo criados nos anos 90. No IFCS/ UFRJ, meu colega J osé R eginaldo Gonçalves vem trabalhando há alguns anos com essa temática, especialmente orientando alunos da pós-graduação em A ntropologia. Em Goiânia, na U niversidade Católica de Goiás, foi criado, por iniciativa do antropólogo M anuel Ferreira Lima Filho, um mestrado profissionalizante em Gestão do Patrimônio Cultural. Esse mestrado conta desde o início com a colaboração de R oque de Barros L araia e é voltado para a profissionalização de gestores de cultura naquela localidade. A lém disso, podemos registrar alguns pólos importantes liderados por antropólogos. É o caso da U niversidade Federal do M aranhão, com A lexandre Corrêa, da U niversidade Federal do Pará, com Jane M aria B eltrão; do M useu Goeldi, com Priscila Faul haber; da U niversidade Federal do Rio Grande do Norte, com Julie Caviganc, e da Universidade Federal do Rio Grande do Sul, com Ruben Georges Oliven e $M$ aria Eunice $M$ aciel. Recentemente, 0 mestrado profissionalizante em Bens Culturais e Projetos Sociais criado no CPD OC veio engrossar a fileira dos cursos voltados para o tema do patrimônio, atuando de forma interdisciplinar e direcionado para um público amplo de profissionais da área da cultura. ${ }^{3}$

Esse trabal ho nas universidades, principalmente nos programas de pós-graduação, vem gerando um número crescente de dissertações e teses e alimentando debates, simpósios e mesas-redondas em todo o país. De tema marginal ou menor nos estudos antropológicos, os estudos de memória, patrimônio e cultura material vêm ganhando visibilidade einserindo-se no movimento contemporâneo de uma antropologia voltada para pensar a sociedade do observador ou, para usar a expressão de M arisa Peirano, de uma antropologia na qual a construção da al teridade é próxima, senão mínima. Este é um campo sem dúvida de interseção entre antropólogos e "outros", dos mais variados lugares e tendências. Campo que se movimenta na confluência entre a academia e as agências de governo, instituições, ONGs e movimentos sociais, entre pesquisas reflexivas e paixões desenfreadas que fazem do patrimônio uma "causa" e uma "bandeira de luta". Esses dois campos interpenetram-se e os limites dessas interferências mútuas são construídos caso a caso.

30 campo da intervenção: a política do patrimônio intangível e a convocação de antropólogos

$\mathrm{Se}$, de um lado, temos um movimento crescente nas universidades, novos debates nacionais e internacionais vêm colocando o tema do patrimônio na ordem do dia das políticas públicas no B rasil e no exterior. Particularmente os antropólogos vêm sendo convocados diante de mudanças significativas nas formulações de políticas do patrimônio, principalmente com 0 fomento ao chamado patrimônio intangível. Não é por acaso que hoje, pela primeira vez na história do I phan, um antropólogo ocupa a presidência da instituição. Vale a pena discorrer sobre al guns aspectos dessa conjuntura que afeta diretamente

\footnotetext{
3. No site do referido mestrado são assim definidos seus objetivos: "O M estrado Profissionalizante em Bens Culturais e Projetos Sociais pretende qualificar profissionalmente aqueles que, tendo concluído o curso de graduação, atuem ou queiram atuar no planejamento, elaboração, desenvolvimento, gestão, assessoramento, difusão, acompanhamento ou avaliação de atividades e propostas voltadas para bens culturais - como acervos, patrimônio, centros de memória e de cultura, exposições e eventos - ou para projetos sociais - em especial aqueles que tomam a cultura como via privilegiada para o desenvolvimento da cidadania e para a redução da exclusão social".
} 
os antropólogos, trazendo novos desafios e possibilidades.

A participação dos antropólogos nas instituições de patrimônio era pequena até bem pouco tempo atrás. N o B rasil, na instituição mais representativa, o I phan, há que se ressaltar a participação de Gilberto Velho no Conselho do Patrimônio, órgão renomado e de grande credibilidade no setor. A política hegemônica do I phan, de sua fundação atéfinal dos anos 90 , privilegiou os tombamentos e a preservação de edificações em "pedra e cal", de conjuntos arquitetônicos e paisagísticos, bem como a proteção a bens móveis e imóveis considerados de relevo para a nação brasileira, seja por expressivas características arquitetônicas, artísticas ou históricas. Tornou-se já um relato mítico para os que contam a história da instituição mencionar as diferenças entre 0 anteprojeto de $M$ ário de A ndrade, esboçado em 1936, e a versão final do Decreto-lei $n^{0} 25$, que instituiu e criou a instituição. De acordo com uma certa corrente de pesquisadores mais simpáticos à visão de $M$ ário de $A$ ndrade, seu anteprojeto conteria uma versão mais culturalista e antropológica, privilegiando uma noção de patrimônio que enfatizava os aspectos mais intangíveis da cultura, como manifestações diversas da cul tura popular. A proposta vencedora, protagonizada na figura de Rodrigo M ello Franco de A ndrade, tenderia a privilegiar os aspectos materiais do patrimônio.

Evidentemente, esse relato mítico da proposta vencida de $M$ ário de Andrade, na disputa com Rodrigo M ello Franco de A ndrade, serve para legitimar a visão de um grupo de gestores do patrimônio que manteve uma oposição ao poder hegemônico no campo, formado em grande parte por arquitetos, e que privilegiou ações de preservação de cunho material pautadas em critérios históricos e artísticos. A s ações mais contundentes do órgão, com repercussões em esferas regionais e locais de preservação e construção da memória no país, consistiram em tombamentos de grandes monumentos, exemplarmente ilustrados pelas igrejas barrocas de Ouro Preto. A breve passagem do designer A loísio $M$ agalhães pela instituição trouxe al gumas idéias novas, com a criação do Centro $\mathrm{N}$ acional de Referências Culturais e a transformação, por um certo período, da instituição de Serviço do Patrimônio Histórico e A rtístico Nacional para Fundação N acional Pró-M emória. A loísio Magalhães adotava uma perspectiva mais culturalista do patrimônio e formou um grupo de colaboradores que faziam uma crítica velada ao que eles consideravam um certo elitismo da proposta até então hegemônica encarnada por Rodrigo. A visão desse grupo era a de que a nação incluía diferentes culturas que deveriam ter seus patrimônios representados em uma instituição voltada para esse fim. Essas diferentes culturas eram expressas em suportes diversos e não apenas os arquitetônicos, que acabaram constituindo o grande elenco de bens preservados.

A morte prematura de A loísio M agalhães e 0 acirramento de disputas internas no órgão impediram que vingasse uma proposta cultural ista do patrimônio, permanecendo a visão até então hegemônica. Entretanto, al guns esforços isolados continuaram a ser implementados. Um dos momentos de destaque dessa disputa consistiu na luta pelo tombamento do terreiro de candomblé Casa Branca na Bahia, onde havia uma árvore sagrada que também deveria ser preservada. A mplo debate processou-se, envolvendo antropólogos, arquitetos e historiadores, que escreveram artigos para um número da Revista do Patrimônio. A rquitetos acostumados com tombamentos de bens móveis e imóveis e não exatamente um local sagrado com as características de um terreiro de candomblé expressaram certa perplexidade com relação ao papel do Estado no caso de um tombamento com aquelas características. A lém do mais, levantavam objeções relativas à fiscalização por parte de um organismo estatal de um espaço cósmico, controlado em última instância pelos desígnios do sobrenatural. E se os santos decidissem que o terreiro deveria migrar para outro local? 0 terreiro deveria ser destombado? E m suma, o terreiro foi tombado, mas a polêmica em torno do caso tornou-se um emblema da contenda entre duas visões de patrimônio.

Durante a passagem de Fernando Collor pel o governo, a instituição, seguindo os mesmos desígnios de outros setores da cultura no país, sofreu um desmonte, com demissões de funcionários, falta de verbas e de uma política clara 
para o setor. A instituição mudou de nome e passou a se chamar Instituto B rasileiro do Patrimônio Cultural, em um sinal evidente que a tendência culturalista continuava a se insinuar em oposição à vertente histórica e artística.

$\mathrm{N}$ os anos do governo de Fernando $\mathrm{H}$ enrique Cardoso, intelectuais e profissionais do campo insistiram que a instituição deveria retomar sua sigla original, com a qual ganhou credibilidade nacional e internacional. Desse modo, a instituição passou a se chamar Instituto do Patrimônio Histórico e Artístico Nacional, nome que permanece até hoje. $M$ as, apesar de a instituição manter no nome a referência ao "histórico e artístico nacional" e não ao "cultural", um movimento novo começou a se insinuar, em grande parte em virtude de novos posicionamentos de organismos internacionais. É importante frisar que, durante os anos que se seguiram à Segunda Guerra M undial, novos organismos internacionais foram criados, como a Unesco, e certos debates, como é o caso dos relativos ao tema do patrimônio, passaram a ser regidos também em conseqüência de reflexões de ordem internacional. Nos anos 90, começaram a surgir com intensidade preocupações relativas ao que os documentos da U nesco chamavam de "culturas tradicionais". Por um lado, levantava-se o temor do desaparecimento dessas culturas em face da mundialização das culturas que tenderiam a homogeneizar e ocidentalizar o planeta. Por outro lado, eram manifestadas preocupações de que os produtores dessas "culturas tradicionais" viessem a ser saqueados por novas modalidades de pirataria na dinâmica do capitalismo global izado. Conhecimentos tradicionais necessários à mani pulação de ervas medicinais, músicas folclóricas, danças tradicionais e outras manifestações dessas culturas ter-se-iam convertido em fontes cobiçadas por um mercado cada vez mais ávido por objetos raros e exóticos.

Novas questões eram levantadas: como salvar essas "culturas tradicionais"? Como munir seus produtores de mecanismos de proteção contra a apropriação de seus acervos de "conhecimentos tradicionais" por parte de um mercado que se globaliza? Em um mundo organizado por patentes, como regular direitos sobre a propriedade intelectual de criações coletivas ou de autoria desconhecida expressa em músicas, rituais, folguedos e manifestações culturais diversas? Como regulamentar juridicamente os direitos relativos aos "conhecimentos tradicionais", uma vez que não há legislação sobre direitos coletivos? Como proteger comunidades que atual izam antigas tradições, tendo em vista que o mercado expande suas fronteiras, delas se apropriando? Em outras palavras, quando uma empresa utiliza padrões gráficos de uma etnia indígena, transformando-os em padrões industriais de tecidos ou quaisquer outros suportes, seria correto ignorar as populações que criaram esses padrões? $\mathrm{Na}$ lógica do capitalismo industrial, não seriam elas as inventoras dos respectivos padrões e, portanto, detentoras legítimas do direito de patente sobre todas e quaisquer utilizações futuras desses bens? 0 mesmo raciocínio não poderia se aplicar a "conhecimentos tradicionais" sobre plantas e ervas medicinais, performances e rituais, técnicas específicas de confecção de instrumentos ou equipamentos e assim por diante? Como adaptar o mecanismo das patentes criadas durante a fase do capital ismo industrial e relacionadas a invenções individuais para um direito de propriedade intelectual coletiva? As sociedades produtoras de "culturas tradicionais" deveriam aderir ao mecanismo das patentes? Haveria como aboli-las?

Estes têm sido al guns temas presentes nos debates promovidos pela U nesco, dos quais participam representantes de diferentes $E$ stadosnações. Em um documento produzido nos anos 90 , sob o título "Recomendações para a proteção e sal vaguarda de manifestações culturais tradicionais", a U nesco fazia al gumas propostas aos países membros da organização. Como antídoto a problemas tão graves, propunha-se que os países membros adotassem algumas medidas, entre elas novas políticas de patrimônio capazes de proteger as chamadas "culturas tradicionais". Especificamente um desses documentos propunha que os países seguissem a inspiração japonesa de proteger o "conhecimento tradicional", as habilidades específicas que são passadas de gerações a gerações de forma ritualizada e por meio de mecanismos próprios. O bservava-se que, no caso japonês, a proteção ao patrimônio não se faz priorizando os resul- 
tados ou produtos de técnicas de construção ou de conhecimentos ancestrais, mas que, pelo contrário, se valoriza o processo do fazer. Desse modo, se um prédio é considerado importante para a cultura japonesa, de tempos em tempos promove-se ritualmente uma desconstrução desse prédio e sua reconstrução. A proteção mais adequada, segundo essa concepção, baseia-se na valorização do processo e não no resultado final. Por outro lado, o documento da U nesco chamava a atenção para a importância de proteger, no caso das "culturas tradicionais", os "mestres" considerados "patrimônios vivos" de conhecimentos muitas vezes não documentados por meio da escrita. Dizia o texto: "Em sociedades tradicionais, quando morre um ancião toda uma biblioteca se queima e se perde para sempre".

Era evidente o surgimento de um dado novo no campo do patrimônio. Se, nos primeiros anos de constituição dos patrimônios nacionais, predominava uma retórica que lastimava a perda de um mundo constituído de prédios e edificações que davam lugar a novos ícones das modernas sociedades urbano-industriais, se nesses anos era preciso salvar algo que testemunhasse momentos da longa trajetória de construção da civilização ocidental, no final dos anos 90, discutia-se um outro sentido para uma mesma retórica da perda. Lastimava-se agora o desaparecimento daqueles que constituíam os "outros" do mundo civilizado, "outros" que expressavam culturas exóticas que teriam sobrevivido a diversas fases do capital ismo, mas que, com a globalização, estariam irremediavel mente fadados à dissolução.

As propostas salvacionistas da Unesco tiveram boa repercussão no $B$ rasil entre gestores do patrimônio, entre eles os segmentos da vertente culturalista do I phan e também de outras agências do M inistério da Cultura. Reuniões foram realizadas, entre elas uma em Fortaleza que congregou técnicos de várias agências governamentais, quando foi proposta a formulação de uma política voltada para o patrimônio intangível. U ma das instituições que aderiu de imediato foi a então Coordenação de Folclore e Cultura Popular, ligada à Funarte, instituição herdeira da Campanha de D efesa do Folclore $B$ rasileiro, atuante desde os anos 50 , e que tinha longa experiência com pesquisa em folclore e cultura popular. Das instituições do M inistério da Cultura, era esta uma das que congregava maior número de antropólogos. Concomitantemente, por ocasião dos festejos dos quinhentos anos do Descobrimento do B rasil, - Ministério da Cultura propôs a Antonio A ugusto $A$ rantes a criação de uma metodologia de inventário das manifestações culturais na região do sul da $B$ ahia, onde havia um projeto de criação de um "Museu A berto do Descobrimento". Gestores do patrimônio interessados na nova política do patrimônio intangível articularam-se no projeto de criação de um programa de ação voltado para o patrimônio intangível no B rasil e, em 4 de agosto de 2000, foi promulgado o Decreto n. 3551, instituindo "o Registro de $B$ ens Culturais de $N$ atureza I material que constituem patrimônio cultural brasileiro e criando 0 Programa N acional do Patrimônio Imaterial".

A proposta do registro significou essencial mente a criação de um selo distintivo oficial para os chamados "bens culturais de natureza imaterial". Evidentemente que, como todo o processo de patrimonialização, essa proposta inclui a idéia de seleção, de construção de um acervo digno de ser memorializado em oposição a um outro conjunto de bens cul turais que devem ser relegados ao esquecimento. A dinâmica patrimonial implica práticas de colecionamento e a prática do registro pode ser comparada à do tombamento, na qual são necessários critérios que possibilitem escol has daquilo que deverá ser preservado.

Para o registro dos bens culturais de natureza imaterial, foram criados quatro livros: 0 Livro do R egistro dos Saberes (para o registro de conhecimentos e modos de fazer); o Livro das Cel ebrações (para as festas, os rituais e os folguedos); o Livro das Formas de Expressão (para a inscrição de manifestações literárias, musicais, plásticas, cênicas e lúdicas) e o Livro dos L ugares (destinado à inscrição de espaços onde se concentram e reproduzem práticas culturais coletivas).

Prevê-se, então, que alguns "bens culturais" devam ser registrados nesses livros e que, como manifestações culturais vivas, eles sejam acompanhados pelos agentes do patrimônio e tenham suas transformações documentadas. 
$N$ as palavras da atual diretora do Departamento do Patrimônio do Iphan, a arquiteta M arcia Sant'A nna,

o registro corresponde à identificação e à produção de conhecimento sobre o bem cultural de natureza imaterial e equivale a documentar, pelos meios técnicos mais adequados, 0 passado e o presente dessas manifestações em suas diferentes versões, tornando tais informações amplamente acessíveis ao público. 0 objetivo é manter o registro da memória desses bens culturais e de sua trajetória no tempo, porque só assim se pode "preservá-los". Como processos culturais dinâmicos, as referidas manifestações implicam uma concepção de preservação diversa daquela prática ocidental, não podendo ser fundada em seus conceitos de permanência e autenticidade. $0 \mathrm{~s}$ bens culturais de natureza imaterial são dotados de uma dinâmica de desenvolvimento e transformação que não cabe nesses conceitos, sendo mais importante, nesses casos, registro e documentação do que intervenção, restauração e conservação. (Sant'A nna, 2003)

Paral elamente ao instrumento do registro, o I phan criou, em parte com as contribuições do projeto piloto desenvolvido por Antonio A ugusto A rantes no sul da Bahia, uma metodologia de inventário que gerou uma proposta de Inventário Nacional de Referências Culturais (INRC), instrumento para subsidiar as ações de registro e realizar um recenseamento amplo das manifestações culturais no país. A na Gita de Oliveira, antropóloga e técnica do I phan, chama a atenção para o fato de que, a partir de 1995,

- Iphan começou a sistematizar os diversos model os de inventários existentes até então e, pela primeira vez, arriscar a difícil tarefa de organizar um inventário que fosse adequado à natureza do patrimônio imaterial [...]. Entre os anos de 1997 e 2000, tendo como fonte de inspiração as experiências realizadas na Fundação Pró-M emória e no desenvolvimento de três experiências de inventários de referências culturais, no Serro/M G, em Diamantina/M G e na cidade de Goiás/G O, se começou a estruturar um modelo de Inventário [...]. (Oliveira, 2004)

A metodologia de inventário sistematizada pelo I phan começou a ser posta em prática por alguns técnicos das agências governamentais, entre eles os técnicos do Centro $\mathrm{Nacional}$ de Folcore e Cultura Popular (CN FCP), sob a coordenação da antropóloga Letícia Vianna. Essa experiência merece ser registrada pois vem abrindo um importante mercado de trabal ho para antropólogos. No caso do projeto do CNFCP, há uma equipe fixa e diversos consultores relacionados a temas específicos que foram selecionados para serem inventariados:

as diferentes celebrações relacionadas ao complexo cultural do boi, os diferentes modos de fazer relacionados ao artesanato em barro; as diferentes formas de expressão e modos de fazer relacionados à musicalidade das violas e percussões; os diferentes modos de fazer relacionados aos sistemas culinários a partir dos elementos mandioca efeijão. (Vianna, 2004)

A maior parte dos envolvidos nessas pesquisas são antropólogos ou estudantes de antropologia em fase de mestrado ou doutorado recrutados em cursos de pós-graduação, que estão envolvidos com teses sobre temas correlatos. 0 objetivo das pesquisas é duplo: tecer um inventário dessas manifestações culturais, escolhidas em parte por retratar certa tradição de estudos da insti tuição, e preparar dossiês para possíveis registros dentro do Programa N acional de Patrimônio Imaterial.

Concomitantemente aos inventários, o mote dos "registros" de manifestações culturais que passariam a ser distinguidas com um selo do M inistério da Cultura vem desencadeando ampla mobilização de profissionais da cultura e agentes sociais em organismos estatais, ONG s e instituições culturais. Com o início da gestão de Gilberto Gil no M inistério da Cultura, houve um incentivo muito grande para que o Programa do Patrimônio I material entrasse em vigor, inclusive com editais de concursos de financiamentos com apoio da Petrobras para pesquisas nessa área. Pode-se falar em uma verdadeira corrida de pesquisadores, principal mente de antropólogos, que se sentiram estimulados a organizar dossiês de pesquisas sobre as manifestações culturais relacionadas aos grupos de seus interesses de pesquisa.

Para que uma manifestação cultural concorra ao registro, é necessário um amplo dossiê 
com pesquisas consistentes, descrições detaIhadas e justificativas sobre as razões dos pedidos de registro. Evidentemente que, para essa atividade específica, os antropól ogos reúnem os atributos necessários. 0 que vem ocorrendo é que antropólogos com maiores informações e condições materiais de realizar tais dossiês levam vantagem em uma certa concorrência para definir que bens culturais serão registrados e receberão o título de "patrimônios culturais do B rasil". Os primeiros casos de "registros de bens culturais" exemplificam esse processo.

0 caso do primeiro bem cultural indígena registrado no Livro dos Saberes do patrimônio imaterial éemblemático. Trata-se do registro da arte kusiwa - pintura corporal e arte gráfica wajãpi, ou seja, de índios habitantes do A mapá e estudados pela antropóloga $\mathrm{D}$ ominique $\mathrm{G}$ allois, do N úcleo de História Indígena e do Indigenismo da USP. A poiada pelo M useu do Índio, por ocasião da elaboração de uma exposição dessa etnia no museu, Dominique Gallois organizou um vasto dossiê, resultado de mais de quinze anos de pesquisa, e o encaminhou, junto com o diretor do M useu do Índio, o também antropólogo J osé Carlos L evinho, ao I phan, solicitando o registro do kusiwa como patrimônio cultural do B rasil, dentro do Programa Nacional do Patrimônio Imaterial. Em um certo sentido, pode-se dizer que, por uma série de motivos, entre eles a agilidade e o trabalho anterior acumulado, D ominique $G$ allois chegou na frente no pedido de registro para a arte gráfica do grupo que estuda e, em 20 de dezembro de 2002, o kusiwa foi registrado como patrimônio cultural do Brasil. Evidentemente que injunções políticas também concorreram para que esse bem cultural recebesse 0 selo de patrimônio oficial pelo governo federal. $\mathrm{N}$ a ocasião, o presidente Fernando Henrique Cardoso encerrava sua gestão e era interessante que o governo mostrasse resultados e a então gestão do Iphan tornasse visível a política que naquele governo começara a adotar.

Com senso de oportunidade e uma pesquisa consolidada sobre os waiãpi, o M useu do Índio, as lideranças indígenas waiãpi e a antropóloga Dominique Gallois emplacaram o registro da bela arte gráfica waiãpi. Entretanto, como assinalou L uiz Fernando D uarte, na época integrante do Conselho do Patrimônio, órgão responsável pela decisão final de tombamentos e registros, o que significa dar um selo oficial de reconhecimento a uma manifestação cul tural se o país é feito de muitas manifestações culturais, todas igualmente significativas para os grupos que a produzem e que por ela são produzidos?

É papel dos antropólogos hierarquizar as culturas? Os antropólogos nos Conselhos de Patrimônio ou nas agências governamentais podem selecionar al gumas manifestações culturais em detrimento de outras? Como patrimonializar as diferenças sem trair o próprio conceito de diferença? Como criar coleções de manifestações culturais dignas de representar a nação brasileira, sabendo que, no mesmo movimento, estamos também praticando 0 descolecionamento, ou seja, criando coleções de manifestações culturais "indignas" de representar a nação brasileira? Cabe ao antropólogo esse papel de certificador das culturas? Quais os significados para o trabalho antropológico quando atuamos como mediadores entre culturas específicas e singulares e agências do governo federal que retiram delas fragmentos para metaforizar uma outra totalidade, a nação total idade que vem sendo construída por agentes especialmente treinados do aparelho de Estado? Como integrar 0 aparelho de Estado, sem perder de vista a premissa básica e fundante de toda a antropologia, que é trabal har com a diferença e buscar traduzi-la sem hierarquizações e etnocentrismos? Como lidar com nossos próprios valores, gostos, idiossincrasias, quando temos diante de nós o poder de certificá-los em detrimento de outros? Por outro lado, como deixar de aproveitar oportunidades de certificar culturas que são nossos próprios objetos de estudo, uma vez que sabemos que elas podem ser boas estratégias para a auto-afirmação e a construção da auto-estima desses grupos? Como fazer isso sem estimular a guerra das culturas em um planeta onde a noção de diversidade cultural vem ganhando o significado do multiculturalismo, ou seja, de culturas fechadas como mônadas ou totalidades que, em muitos casos, perdem quaisquer referências ao objetivo do entendimento humano? A inda refletindo sobre o caso do grafismo waiãpi e sem tirar o mérito e a beleza dessa arte gráfica, como proceder diante de todas as demais artes gráficas das etnias 
indígenas no Brasil, uma vez que todas elas produzem artes gráficas igualmente belas e culturalmente significativas? Não estaríamos também correndo o risco de engessar as manifestações culturais, congelando-as com base na imagem cristal izada no registro?

\section{Conclusão}

Estas são algumas questões sobre as quais os antropólogos do patrimônio devem refletir nos próximos anos. Não são questões de fácil resposta. É preciso ter em mente que, se hoje abre-se um mercado extraordinário para a antropologia com as novas demandas do campo do patrimônio, não devemos nele nos inserir sem crítica e atitude reflexiva. A final, o que notabilizou a disciplina durante praticamente um século de atividades foi exatamente um certo olhar ao mesmo tempo complacente e relativizador diante das criações humanas. Parafraseando Lévi-Strauss em um texto clássico sobre a diversidade das culturas, eu ainda partil haria do ponto de vista de que a diversidade da culturas humanas está diante de nós e atrás de nós e uma das exigências que deveríamos fazer valer a esse respeito é que o registro da contribuição de cada uma seja apenas mais uma lembrança da generosidade das outras para esse grande acervo da contribuição humana à plasticidade da vida do planeta (Lévi Strauss, 1970).

Abstract: The number of anthropologists investigating the field of altural heritage is growing. These researchers have contributed to accurate analysis about questions of values and their attributes in the social context. It is supposed that altural goods as altural heritage have a strong symbolic content, capable to express and/or represent nations, regions, ethnies and social groups. On the other side, the fact that the field of heritage became a field of intervention brings often different interests and demands to the reflexive perspective of anthropologists. W e can scrutinize current trends and tendencies between the anthropologists who research, reflect and work with heritage and the anthropologists who see themselves as active agents of heritage. In the recent years, the tensions and/or interactions between reflexive activities and practical activities have won new features in both national and intemational contexts, especially with the implementation to inventory and registry of the so-called intangible heritage. Partiaularly in this field, the anthropologists have hardly assumed to establish criterions and develop methodblogies capable to enlarge the heritage process of altural diversities. This article aims to scrutinize the different positions of anthropologists investigating heritage and then to discuss the tensions and/or articulations among the diverse sets of reflexive and/or practical procedures.

K ey-words: heritage; anthropology; social memory .

\section{R eferências}

A BREU, Regina. A fabricação do imortal - memória, história e estratégias de consagração no B rasil. Rio deJ aneiro: Ed. Rocco/L apa, 1996.

. História de uma col eção: M iguel Cal mon e o M useu Histórico Nacional. Anais do M useu Paulista. História e Cultura M aterial. J an./dez. 1994, SP, USP.

. Síndrome de museus. Encontros e Estudos 2, Funarte, M inC, 1996.

A NDERSON, Benedict. Imagined communities. N orfolk: Thetford Press, 1987.

A RA NTES, A. A . Produzindo o passado. São Paulo: B rasiliense, 1984.

CARVA LHO, J osé M urilo de. A formação das almas. 0 imaginário da República no Brasil. São Paulo: Companhia das L etras, 1990.

CHAGAS, M. Há uma gota de sangue em cada museu: a ótica museológica de M ário de A ndrade. Cadernos de Sociomuseologia, n. 13, Lisboa, ULHT, 1999.

CLIFFORD, James. Colecionando arte e cultura. Revista do Patrimônio Histórico e Artístico Nacional, 1995.

. M useologia e contra-história. Viagens pela Costa Noroeste. In: A BREU, Regina; CHAGAS, $M$ ário. M emória e patrimônio. Rio de Janeiro: Ed. DPA, 2003

CHUVA, Márcia. Os arquitetos do patrimônio. [Mimeo.]

FONSECA, M aria Cecília L ondres. 0 patrimônio em processo. Trajetória da política federal de preservação no Brasil. Rio de Janeiro: Ed. UFRJ/M incIphan, 1997.

GONÇA LVES, J osé Reginaldo. A utenticidade, memória eideologias nacionais. Estudos $\mathrm{H}$ istóricos, n. 2, 1988.

. 0 jogo da autenticidade: nação e patrimônio cultural no Brasil. In: I deólogos do patrimônio cultural. Rio de J aneiro: IB PC, 1991. 

$\overline{19} \overline{9} \overline{6}$.

Retórica da perda. Rio de J aneiro: Ed. UFRJ,

HOBSBAW M , Eric]. Nações e nacionalismo desde 1780: programa, mito e realidade. Rio de Janeiro: Paz eTerra, 1990.

; RANGER, Terence. A invenção das tradições. Rio de J aneiro: Paz e Terra, 1984.

LÉVI-STRA USS, Claude. Raça e história. In: COMAS, J uan et al. (O rgs.) Raça e ciência I. São Paulo: E ditora Perspectiva, 1970.

MENEZES, UIpiano T. Bezerra de. Do teatro da memória ao laboratório da história: a exposição museológica e o conhecimento histórico. Anais do M useu Paulista. História e Cultura M aterial. Jan./ dez. 1994, SP, Ed. USP.

NORA, P. M émoire et histoire - la problematique des lieux. Les lieux de mémoire. Paris: Gallimard, 1984.

SANT'ANNA, Marcia. A face imaterial do patrimônio cultural. In: ABREU, Regina; CHAGAS, $M$ ário. M emória e patrimônio, Rio de Janeiro: Ed. DPA, 2003.

OLIVEIRA, A na Gita de. Diversidade cultural como categoria organizadora de políticas públicas. In: TEIXEIRA , J oão Gabriel etal. P atrimônio imaterial, performance cultural e (re)tradicionalização. B rasília: Transe/Ceam, 2004.

SANTOS, M yrian S. dos. História, tempo e memória: um estudo sobre museus a partir da observação feita no M useu Imperial e no M useu Histórico Nacional. Rio de Janeiro, 1989. Dissertação (M estrado) IUPERJ.

. O pesadelo da amnésia coletiva: um estudo sobre os conceitos de memória, tradição e traços do passado. RCBS, n. 23, p. 71-84, out. 1993.

SCHWA RCZ, Lilia K.M . 0 nascimento dos museus brasileiros, 1870-1910. In: M ICELI, Sérgio (Org.). História das ciências sociais no Brasil. São Paulo: Finep/V értice, 1989, v. I.

0 espetáculo das raças: cientistas, instituições equestão racial no B rasil - 1870-1930. São Paulo: Companhia das L etras, 1995.

STOCKING, Jr., George W. Objects and others. Essays on museums and material culture. London: U niversity of Wisconsin Press, 1985.

VIA N N A, L etícia. Pluralidade cultural e identidade nacional: experiências recentes de políticas no $B$ rasil. In: TEIXEIRA, João Gabriel et al. Patrimônio imaterial, performance cultural e (re)tradicionalização. B rasília: Transe/C eam, 2004. 